\title{
Physicochemical and Microstructural Characterization of Whey Protein Films Formed with Oxidized Ferulic/Tannic Acids
}

\author{
Yaosong Wang ${ }^{1,2}$ and Youling L. Xiong ${ }^{3, * \mathbb{D}}$ \\ 1 Department of Food Science and Engineering, College of Light Industry and Food Engineering, \\ Nanjing Forestry University, Nanjing 210037, China; yaosongwang@njfu.edu.cn \\ 2 State Key Laboratory of Food Science and Technology, Jiangnan University, Wuxi 214122, China \\ 3 Department of Animal and Food Sciences, University of Kentucky, Lexington, KY 40546, USA \\ * Correspondence: ylxiong@uky.edu; Tel.: +1-859-257-5318
}

Citation: Wang, Y.; Xiong, Y.L.

Physicochemical and Microstructural Characterization of Whey Protein Films Formed with Oxidized Ferulic/Tannic Acids. Foods 2021, 10, 1599. https://doi.org/10.3390/ foods10071599

Academic Editor: Laurent Bazinet

Received: 4 June 2021

Accepted: 5 July 2021

Published: 9 July 2021

Publisher's Note: MDPI stays neutral with regard to jurisdictional claims in published maps and institutional affiliations.

Copyright: (C) 2021 by the authors Licensee MDPI, Basel, Switzerland. This article is an open access article distributed under the terms and conditions of the Creative Commons Attribution (CC BY) license (https:/ / creativecommons.org/licenses/by/ $4.0 /)$

\begin{abstract}
Protein-based biodegradable packaging films are of environmental significance. The effect of oxidized ferulic acid (OFA)/tannic acid (OTA) on the crosslinking and film-forming properties of whey protein isolate (WPI) was investigated. Both of the oxidized acids induced protein oxidation and promoted WPI crosslinking through the actions of quinone carbonyl and protein sulfhydryl, and amino groups. OTA enhanced the tensile strength (from 4.5 MPa to max 6.7 MPa) and stiffness (from $215 \mathrm{MPa}$ to $\max 376 \mathrm{MPa}$ ) of the WPI film, whereas OFA significantly increased the elongation at break. The water absorption capability and heat resistance of the films were greatly improved by the addition of OTA. Due to the original color of OTA, the incorporation of OTA significantly reduced light transmittance of the WPI film $(\lambda 200-600 \mathrm{~nm})$ as well as the transparency, whereas no significant changes were induced by the OFA treatment. Higher concentrations of OTA reduced the in vitro digestibility of the WPI film, while the addition of OFA had no significant effect. Overall, these two oxidized polyphenols promoted the crosslinking of WPI and modified the film properties, with OTA showing an overall stronger efficacy than OFA due to more functional groups available.
\end{abstract}

Keywords: whey protein; edible film; oxidized polyphenols; crosslinking; morphology

\section{Introduction}

Biodegradable packaging materials are being developed as a part of "future food" to partially replace traditional nondegradable materials, to reduce environmental pollution [1]. Of the different biodegradable materials, whey protein has received considerable attention, due to its film-forming potential [2]. Whey protein is capable of forming a barrier film with high transparency, a uniform texture, and flexibility [3,4]. However, unlike plastic packaging materials made of polymerized organic molecules, edible films made from native proteins lack structural integrity and mechanical strength $[5,6]$. To mitigate the deficiency, methods that are capable of modifying the reactive side-chain groups in proteins are recommended, i.e., physical, chemical, or enzymatic treatments [7].

Protein crosslinking is considered to be an effective approach in achieving desirable functionality for film production [8]. Suitable crosslinkers include a variety of natural compounds that prove to be safe and present minimal risk. Phenolics, one of such compounds that are widely available, are a large class of non-toxic, antioxidative, and edible natural products, of which many exhibit health benefits [9]. In food processing, polyphenols are readily oxidized to electrophilic quinones, which can subsequently crosslink with proteins [10]. Previous studies have shown that ferulic and tannic acids, two widely distributed natural phenols, have antimicrobial and antioxidant activity [11,12]. Both also have the potential to improve the mechanical properties and decrease the water vapor permeability of collagen- or gelatin-based films $[13,14]$. Oxidized tannic acid also strongly affects the mechanical strength, surface hydrophobicity, and hydration of zein-based films [15]. Ferulic acid is capable of decreasing the oxygen permeability of whey protein films [4], 
while tannic acid is able to crosslink caseins [16] and $\beta$-lactoglobulin ( $\beta \mathrm{Lg}$ ) [17], leading to significantly improved overall physicochemical properties of such edible film products.

Due to the electrophilic nature of quinone carbonyls and the abundant presence of nucleophiles in whey protein (sulfhydryl and amine groups), it can be hypothesized that the quinone species derived from oxidized ferulic or tannic acids are more efficient to crosslink whey proteins to produce functional protein films. To the best of our knowledge, few studies have been conducted to investigate the impact of oxidized phenolic acids on the crosslinking of whey protein in edible film production. In this context, the objective of our resent work was to employ oxidatively modified ferulic/tannic acids to crosslink whey protein for an enhanced film with improved physicochemical properties. The digestive performance and microstructure of the resulting films were also investigated.

\section{Materials and Methods}

\subsection{Materials and Chemicals}

Whey protein isolate (WPI, 90\% protein) was obtained from Hilmar Ingredients (Hilmar, CA, USA). Pepsin and pancreatin $(8 \times$ USP) were purchased from Sigma-Aldrich, Inc. (St. Louis, MO, USA). Ferulic acid $\left(\mathrm{C}_{10} \mathrm{H}_{10} \mathrm{O}_{4}\right.$, a monophenol with a molecular mass of 194.2) and tannic acid $\left(\mathrm{C}_{76} \mathrm{H}_{52} \mathrm{H}_{46}\right.$, a decagalloyl or decaphenol with a molecular mass of 1701.2) were purchased from Sinopharm Chemical Reagent Co. Ltd. (Shanghai, China). All other chemicals and reagents, of analytical grade unless otherwise specified, were purchased from Sigma-Aldrich (St. Louis, MO, USA) or Sinopharm Chemical Reagent Co. Ltd. (Shanghai, China).

\subsection{Oxidation Phenolic Acids}

The oxidized ferulic and tannic acids were prepared according to the method described in a previous study [18] with slight modifications. Ferulic and tannic acids (1.125 g) were dissolved in $45 \mathrm{~mL}$ deionized water at $60{ }^{\circ} \mathrm{C}$ with gentle stirring. The solutions were adjusted to $\mathrm{pH} 9.0$ with $1 \mathrm{~N} \mathrm{NaOH}$ and then incubated in a $50{ }^{\circ} \mathrm{C}$ water bath. The solutions were bubbled with oxygen during the reaction for up to $3.5 \mathrm{~h}$ to convert both acids to quinones.

\subsection{Film-Forming Solutions Preparation and Film Casting}

Aqueous WPI solutions $(6 \%, w / v)$ were adjusted to $\mathrm{pH} 8.0$ using $1 \mathrm{M} \mathrm{NaOH}$ and then heated at $90^{\circ} \mathrm{C}$ for $30 \mathrm{~min}$ in a water bath to unfold protein. After cooling to room temperature $\left(23^{\circ} \mathrm{C}\right)$, prepared phenolic compounds $(0,2.5$, and $5.0 \% w / w$, protein weight basis) were added. The mixtures were stirred at room temperature for $1 \mathrm{~h}$, and the plasticizer glycerol $(2.4 \% w / v$, final concentration) was then incorporated and gently mixed. Prior to cast, the solutions were degassed under vacuum for $10 \mathrm{~min}$ to remove air. Aliquots were poured onto leveled plexiglass plates and spread evenly with a glass rod [3]. Films were dried in a humidity-controlled chamber (PGC Parameter Generation \& Control, Inc., Black Mountain, NC, USA) with a $50 \pm 2 \%$ relative humidity (RH) at $23{ }^{\circ} \mathrm{C}$ for $24 \mathrm{~h}$ and then peeled for subsequent evaluation.

\subsection{Measurement of Protein Changes}

\subsubsection{Total Sulfhydryl Content and Free Amines}

Total sulfhydryls (SH) were measured using 5,5'-dithiobis (2-nitrobenzoic acid) (DTNB) as previously described [19]. The absorbance at $412 \mathrm{~nm}$ was measured against a blank of DTNB at the same concentration without protein. Total sulfhydryl concentration was calculated using a molar absorption coefficient of $13,600 \mathrm{M}^{-1} \mathrm{~cm}^{-1}$ and expressed as nmol sulfhydryls per mg protein. Free amines $\left(\mathrm{NH}_{2}\right)$ were quantified according to the colorimetric reaction with trinitrobenzenesulfonic acid (TNBS) [20]. WPI samples were diluted to $1 \%$ in $2.0 \mathrm{~mL}$ of $0.2 \mathrm{M}$ phosphate buffer (pH 8.2), and $1.0 \mathrm{~mL}$ of $0.01 \%$ TNBS solution was added. The mixture was incubated at $50{ }^{\circ} \mathrm{C}$ for $30 \mathrm{~min}$ in the dark before $2 \mathrm{~mL}$ of $0.1 \mathrm{M}$ sodium sulfite was added to terminate the reaction. Absorbance at $420 \mathrm{~nm}$ was then 
measured, and the free-amine content was calculated as $\mu \mathrm{mol}$ amines per mg protein using a standard curve constructed from L-leucine.

\subsubsection{Surface Hydrophobicity}

Surface hydrophobicity as an indicator of protein reactive nonpolar group exposure was determined using a fluorescence probe, 8-anilino-1-naphthalene sulfonic acid (ANS) [21]. WPI samples were diluted to $10 \mathrm{mg} / \mathrm{mL}$, and $4 \mathrm{~mL}$ of the solution was reacted with $0.4 \mathrm{~mL}$ of $0.04 \%$ ANS for $15 \mathrm{~min}$ at room temperature. Fluorescence intensity was measured using a Hitachi 650-60 fluorescence spectrophotometer (Hitachi Ltd., Tokyo, Japan) with an excitation wavelength of $365 \mathrm{~nm}$ and emission wavelength of $470 \mathrm{~nm}$.

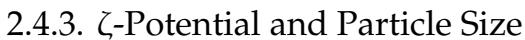

A Mastersizer Nano ZS instrument (Malvern Instruments, Worcestershire, UK) was used to measure $\zeta$-potential and particle size distribution of WPI cast solutions. The protein concentration was diluted to $1 \mathrm{mg} / \mathrm{mL}$ using $10 \mathrm{mM}$ phosphates buffer (pH 7.0). A $1 \mathrm{~mL}$ sample was used to measure the particle size and $\zeta$-potential at $25^{\circ} \mathrm{C}$ after 2 min quiescent equilibrium post sampling. The values of $\zeta$-potential and mean diameter $Z$-average were expressed as the average of three freshly prepared cast solution samples.

\subsubsection{Sodium Dodecyl-Sulfate Polyacrylamide Gel Electrophoresis (SDS-PAGE)}

Electrophoresis was performed according to the method of Laemmli [22] using a $5 \%$ acrylamide stacking gel and $12.5 \%$ acrylamide separating gel. The gel was stained with $0.1 \%$ (m/v) Coomassie brilliant blue (R250) in 50\% methanol and $6.8 \%$ glacial acetic acid solution for $4 \mathrm{~h}$ and subsequently destained with a 7.5\% glacial acetic acid and 10\% methanol solution.

\subsection{Assessment of Film Properties}

\subsubsection{Mechanical Properties}

Prior to measurement, films were conditioned in the humidity-controlled chamber (RH $50 \pm 2 \%$ ) at $23{ }^{\circ} \mathrm{C}$. A TA.XT plus texture analyzer (Stable Micro Systems Ltd., Godalming, UK) was used to determine tensile strength (TS), elongation at break (EAB), and Young's modulus according to ASTM [23] standard method. Samples were prepared by cutting into $1.9 \mathrm{~cm} \times 10 \mathrm{~cm}$ strips using a sharp knife and then mounted to the texture analyzer. A $50 \mathrm{~N}$ load cell was used to test the films at a pull rate of $50 \mathrm{~mm} / \mathrm{min}$. TS and EAB were calculated from the curve of the force versus distance.

\subsubsection{Swelling}

Preconditioned $\left(23{ }^{\circ} \mathrm{C}, 50 \pm 2 \% \mathrm{RH}\right)$ films were cut into $2.5 \times 2.5 \mathrm{~cm}^{2}$ squares and immersed in $100 \mathrm{~mL}$ of warm $\left(40^{\circ} \mathrm{C}\right)$ deionized water for $30 \mathrm{~min}$. After blotting with filter paper, the film samples were weighed. The degree of swelling was calculated according to Equation (1):

$$
S(\%)=\frac{W_{2}-W_{1}}{W_{1}} \times 100 \%
$$

where $W_{1}$ and $W_{2}$ are the original and swollen weights, respectively.

\subsubsection{Water Vapor Permeability (WVP)}

WVP was determined gravimetrically according to ASTM [24]. Films were mechanically mounted onto a beaker (height: $6 \mathrm{~cm} ; \mathrm{d}=3.3 \mathrm{~cm}$ ) filled with silica gel at $5 \mathrm{~cm}$ of depth. The beakers were placed in the $50 \% \mathrm{RH}$ chamber at $23{ }^{\circ} \mathrm{C}$. The weight of beakers was measured at $2 \mathrm{~h}$ intervals for a total of $12 \mathrm{~h}$. WVP was calculated according to Equation (2):

$$
W V P=\frac{W \times x}{t \times A \times \Delta p}
$$


where $W$ is the weight gain within $12 \mathrm{~h}(t), x$ is the film thickness $(\mathrm{mm}), A$ is the area of exposed films $\left(\mathrm{m}^{2}\right)$, and $\Delta p$ is the difference in vapor pressure across the film equal to $1.4052 \times 10^{3} \mathrm{~Pa}$.

\subsubsection{Microstructure and Morphology}

The fine structure of film cross-sections was characterized by using scanning electron microscopy (SEM, Quanta-200 scanning electron microscope, Hillsboro, OR, USA). The film was mounted on a bronze stub and sputter-coated with gold prior to imaging.

For film surface morphology characterization, atomic force microscopy (AFM) was conducted using an MFP-3D-SA AFM machine (Asylum Research, Goleta, CA, USA) in the tapping mode. Roughness $(R q)$ was calculated according to Equation (3):

$$
R_{q}=\sqrt{\frac{\sum_{i=1}^{N}\left(Z_{i}-\bar{Z}\right)^{2}}{N}} \text { and } \bar{Z}=\frac{1}{N} \sum_{i=1}^{N} Z_{i}
$$

where $Z_{i}$ is the height of values profile (histogram, nm), $\bar{Z}$ is the arithmetic mean of heights $(\mathrm{nm})$, and $N$ is the number of data points in the profile.

\subsubsection{Light Transmittance and Transparency}

The ultraviolet (UV) and visible-light barrier properties of WPI films were measured at 200-800 nm using a UV-visible spectrophotometer (Gary50, Varian, Palo Alto, CA, USA). Film transparency was calculated as in Equation (4):

$$
T=-\log T_{600} / x
$$

where $T_{600}$ is the fractional transmittance at $600 \mathrm{~nm}$, and $x$ is the film thickness (mm).

\subsubsection{Thermal Properties}

Differential scanning calorimetry (DSC) was conducted to determine the thermal transition temperatures of the films [25] using a Q2000 DSC machine (TA Instruments, New Castle, DE, USA). Approximately $3 \mathrm{mg}$ of film samples were placed in an aluminum pan and hermitically sealed. Samples were heated from $25^{\circ} \mathrm{C}$ to $260^{\circ} \mathrm{C}$ at a rate of $20^{\circ} \mathrm{C}$ per min. An empty sample pan was used as reference. The transition temperatures (onset, $T_{0}$; peak, $T_{\mathrm{p}}$; and end, $T_{\mathrm{d}}$ ) and enthalpy of melting $(\Delta H)$ were determined from the thermograms using Universal Analysis 2000 software (v. 4.5A, Build 4.5.0.5) supplied by TA Instruments (New Castle, DE, USA).

\subsubsection{Film Protein Leachability}

Films were trimmed into $2.0 \times 2.4 \mathrm{~cm}$ strips, individually submerged in $10 \mathrm{~mL}$

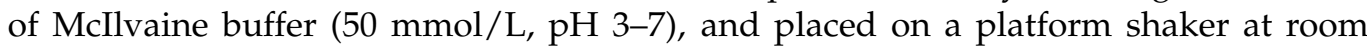
temperature for $24 \mathrm{~h}$. The leached proteins were quantified by the Biuret method. The leachability was expressed as the ratio of protein released into the solution versus the total protein in the original film. The supernatant containing leached proteins was also subjected to SDS-PAGE analysis.

\subsubsection{Film Digestibility}

Proteolytic digestion of the films was performed using gastrointestinal enzymes [26]. Aliquots $(0.2 \mathrm{~g}$ ) of ground film pieces were transferred into $100 \mathrm{~mL}$ Erlenmeyer flasks to which $50 \mathrm{~mL}$ of deionized water was added. After adjusting the $\mathrm{pH}$ to 2.0 using $1 \mathrm{~N} \mathrm{HCl}$, the film samples were incubated at $37^{\circ} \mathrm{C}$ for $60 \mathrm{~min}$ then centrifuged at $5000 \times \mathrm{g}$ for $15 \mathrm{~min}$. Leached protein (supernatant) was measured, and unleached protein (\%) was calculated as follows: [(total film protein-leached protein)/total film protein] $\times 100$. Pepsin $(4 \%, w / w$, protein basis) was then added. The mixture was incubated $1 \mathrm{~h}$ in a shaking water bath at $37^{\circ} \mathrm{C}$. Subsequently, the gastric digest was adjusted to $\mathrm{pH} 7.5$ by the addition of $0.9 \mathrm{M}$ 
$\mathrm{NaHCO}_{3}$, and pancreatin ( $4 \% \mathrm{w} / \mathrm{w}$, protein basis) was then added. The solutions were incubated at $37^{\circ} \mathrm{C}$ for up to $4 \mathrm{~h}$. At $0,30,60,90,120,180$, and $240 \mathrm{~min}, 2.5 \mathrm{~mL}$ aliquots were taken and $1 \mathrm{~mL}$ of $50 \%(w / w)$ trichloroacetic acid (TCA) was added to terminate the digestion. All inactivated samples were stored at $4{ }^{\circ} \mathrm{C}$ for $18 \mathrm{~h}$ and then centrifuged at $5000 \times g$ for $15 \mathrm{~min}$. The protein (peptide) concentration of the supernatant was determined by the Biuret method. The percentage of enzyme-released protein over the total amount of unleached protein (i.e., remaining in the film prior to pepsin addition) was designated as the digestibility or digestion rate $(\%)$.

\subsection{Statistical Analysis}

The experiments were conducted in triplicate, each with at least duplicate sample analyses. Data were subjected to the analysis of variance using the Statistix software 9.0 (Analytical Software, Tallahassee, FL, USA) adopting a general linear model procedure. Significant $(p<0.05)$ differences between means were identified by LSD all-pairwise multiple comparisons.

\section{Results and Discussion}

\subsection{Protein Modification and Physicochemical Changes of Film-Forming Solutions}

Susceptible to reactive oxygen species (ROS), protein side-chain groups are an easy target, and serve as the basis for crosslinking reactions with polyphenols under oxidative conditions [27,28]. In particular, sulfhydryl, free-amine, indolyl, and imidazolyl groups are involved in covalent reactions between proteins and phenolic compounds [29]. In the present study, oxidized ferulic acid (OFA) and, more so, oxidized tannic acid (OTA) showed a major, dose-dependent effect on sulfhydryls and free amines (Table 1). The loss of the two protein side-chain groups ranged from 24.7 to 94.7 for $\mathrm{SH}$, and from 5.1 to $25.3 \%$ for $\mathrm{NH}_{2}(p<0.05)$. The most likely cause was electrophilic attack by both the quinone species. While OFA did not affect protein surface hydrophobicity, OTA significantly decreased the value, due to the induction of protein aggregation, which was evinced by the marked increase in protein particle size (Table 1). The stronger efficacy of OTA was attributed to the polygalloyl structure (10 phenol groups) of tannic acid compared with only one phenol in ferulic acid; hence, the potential of generating highly reactive polycarbonyls when oxidized. The particle size increase can be caused by a number of forces promoted by the presence of oxidized phenolic compounds, including disulfide linkages, hydrogen bonds, and van der Waals force, as well as protein-phenol complexation [10]. These physicochemical modifications did not have a significant effect on protein charge distribution ( $\zeta$-potential). The structural changes and crosslinking reactions induced by oxidized phenolic acids would conceivably modulate the film-forming ability of WPI.

Table 1. Physicochemical changes in oxidized ferulic (OFA) and tannic (OTA) acid-treated WPI.

\begin{tabular}{|c|c|c|c|c|c|}
\hline \multirow{2}{*}{ Parameter } & \multirow{2}{*}{ Control } & \multicolumn{2}{|c|}{ OFA $(w / w)$} & \multicolumn{2}{|c|}{ OTA $(\%, w / w)$} \\
\hline & & $2.5 \%$ & $5.0 \%$ & $2.5 \%$ & $5.0 \%$ \\
\hline $\begin{array}{l}\mathrm{SH}(\mathrm{nmol} / \mathrm{mg} \\
\text { protein) }\end{array}$ & $21.8 \pm 0.3^{a}$ & $16.4 \pm 0.5^{b}$ & $11.4 \pm 0.2^{\mathrm{c}}$ & $4.2 \pm 0.2^{\mathrm{d}}$ & $1.2 \pm 1.5^{\mathrm{e}}$ \\
\hline 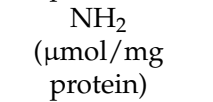 & $0.79 \pm 0.02^{\mathrm{a}}$ & $0.75 \pm 0.02^{b}$ & $0.72 \pm 0.01^{\mathrm{b}}$ & $0.62 \pm 0.01^{c}$ & $0.59 \pm 0.01^{\mathrm{d}}$ \\
\hline Hydrophobicity & $2.59 \pm 0.16^{\mathrm{a}}$ & $2.62 \pm 0.07^{a}$ & $2.48 \pm 0.07^{\mathrm{a}}$ & $1.94 \pm 0.02^{b}$ & $1.72 \pm 0.05^{c}$ \\
\hline $\begin{array}{c}\text { Particle size } \\
\text { (nm) }\end{array}$ & $85 \pm 9^{a, b}$ & $78 \pm 1^{b}$ & $83 \pm 6^{b}$ & $117 \pm 18^{a}$ & $112 \pm 48^{\mathrm{a}}$ \\
\hline $\begin{array}{l}\zeta \text {-potential } \\
(\mathrm{mV})\end{array}$ & $-26.6 \pm 1.9^{a}$ & $-26.5 \pm 2.2^{a}$ & $-25.5 \pm 1.8^{a}$ & $-24.8 \pm 1.7^{\mathrm{a}}$ & $-25.6 \pm 2.4^{a}$ \\
\hline
\end{tabular}

$\overline{\mathrm{a}-\mathrm{e}}$ Means $\pm \mathrm{SD}(n=3)$ in the same row that do not share a common superscript differ significantly $(p<0.05)$. SH: sulfhydryls; $\mathrm{NH}_{2}$ : free amines.

To detect covalent cross-linkages between the protein molecules, caused by the oxidized phenols, electrophoresis under reducing (with $\beta$-mercaptoethanol, $+\beta \mathrm{ME}$ ), and 
non-reducing (without $\beta$-mercaptoethanol, $-\beta M E$ ) conditions was performed (Figure 1). All the WPI samples, regardless of phenol treatment, displayed a prominent $\beta \mathrm{Lg}$ band and its dimer. However, protein polymers accumulating as smears, near the top of the separating gel, were ostensibly more intense in oxidized WPI than in the control sample, indicating covalent crosslinking. The oxidative effect of OFA and OTA differed considerably. For the samples treated with OFA, there were no remarkable changes in the protein pattern $(-\beta \mathrm{ME})$. Although largely broken down under reducing conditions $(+\beta \mathrm{ME})$, the $\beta \mathrm{Lg}$ dimer remained salient in the OFA-treated samples, suggesting secondary crosslinking via quinones other than the primary disulfide bonds. These electrophoretic changes were more noticeably pronounced when WPI was treated by OTA, which included the disappearance of $\beta \mathrm{Lg}$, OTA-crosslinked $\beta \mathrm{Lg}$ dimer, and the formation of protein polymers. Previous studies had shown that phenols and their oxidized quinone forms could react with proteins via $\mathrm{C}-\mathrm{N}$ or $\mathrm{C}-\mathrm{S}$ bonds $[30,31]$. Our results, in support of those previous reports, were also consistent with the observed decline in both the $\mathrm{SH}$ and the $\mathrm{NH}_{2}$ groups (Table 1).

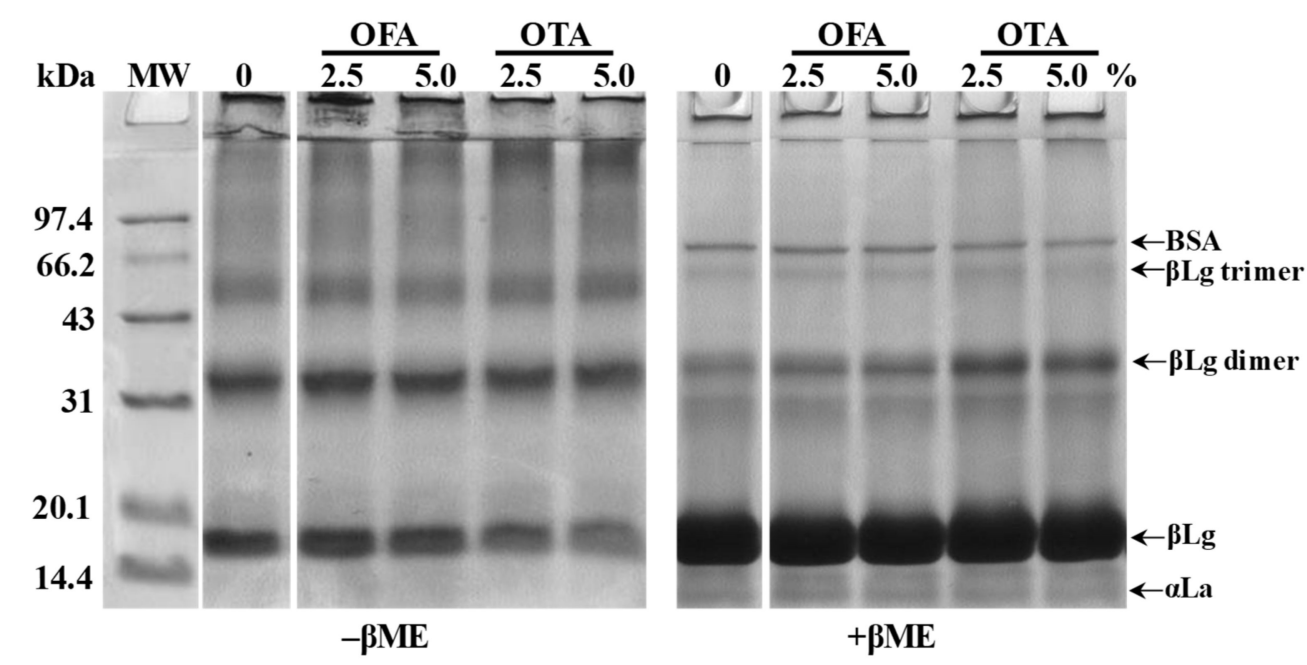

Figure 1. Sodium dodecyl-sulfate polyacrylamide gel electrophoresis (SDS-PAGE) of whey protein isolate (WPI) treated with $2.5 \%$ and $5.0 \%$ oxidized ferulic (OFA) and tannic (OTA) acids under non-reducing $(-\beta \mathrm{ME})$ and reducing (+ $\beta \mathrm{ME})$ conditions. MW: molecular weight; BSA: bovine serum albumin; $\beta$ Lg: $\beta$-lactoglobulin; $\alpha$ La: $\alpha$-lactalbumin; $\beta$ ME: $\beta$-mercaptoethanol.

\subsection{Mechanical Properties}

Tensile strength (TS), elongation at break (EAB), and Young's modulus (modulus of elasticity) are commonly used to describe the mechanical properties and structural integrity of protein films [5]. These parameters are considered in the handling, processing, and storage of films when applied to practical foods. The addition of oxidized phenolics significantly improved TS and Young's modulus, especially by OTA $(p<0.05)$, and there was no difference between the $2.5 \%$ and $5.0 \%$ dosage levels (Table 2). While EAB was greatly increased by OFA, suggesting a strong film elasticity, it was not significantly affected by OTA. The inherent changes in a molecule, such as polypeptide stretching [32] and the hydrophobicity of phenol-bound proteins [33], could affect the mechanical properties. Oxidized phenolics can induce protein aggregation and react with proteins via nucleophilic pathways to form $\mathrm{C}-\mathrm{N}$ or $\mathrm{C}-\mathrm{S}$ through quinone carbonyls, leading to protein crosslinking [30]. These changes likely accounted for the observed improvements in the mechanical properties of the oxidized WPI films in our study. 
Table 2. Mechanical and selective physical properties of oxidized ferulic (OFA) and tannic (OTA) acid-treated WPI films.

\begin{tabular}{|c|c|c|c|c|c|}
\hline \multirow{2}{*}{ Property } & \multirow{2}{*}{ Control } & \multicolumn{2}{|c|}{ OFA $(w / w)$} & \multicolumn{2}{|c|}{ OTA $(\%, w / w)$} \\
\hline & & $2.5 \%$ & $5.0 \%$ & $2.5 \%$ & $5.0 \%$ \\
\hline TS (MPa) & $4.5 \pm 0.2^{c}$ & $4.9 \pm 0.7^{b, c}$ & $5.2 \pm 0.5^{b}$ & $6.7 \pm 0.3^{a}$ & $6.7 \pm 0.40^{a}$ \\
\hline $\mathrm{EAB}(\%)$ & $24.2 \pm 4.1^{b}$ & $34.9 \pm 10.0^{\mathrm{a}}$ & $35.5 \pm 11.9^{a}$ & $20.5 \pm 4.3^{b}$ & $15.2 \pm 1.8^{b}$ \\
\hline $\begin{array}{l}\text { Young's } \\
\text { modulus } \\
(\mathrm{MPa})\end{array}$ & $190 \pm 11^{c}$ & $215 \pm 22^{b, c}$ & $238 \pm 26^{b}$ & $358 \pm 19^{a}$ & $376 \pm 4^{\mathrm{a}}$ \\
\hline Swelling & $139 \pm 61^{b}$ & $171 \pm 48^{b}$ & $193 \pm 7^{b}$ & $325 \pm 21^{a}$ & $318 \pm 86^{a}$ \\
\hline $\begin{array}{c}\text { WVP } \\
\left(\mathrm{g} \cdot \mathrm{mm} / \mathrm{kPa} \cdot \mathrm{h} \cdot \mathrm{m}^{2}\right)\end{array}$ & $1.02 \pm 0.21^{\mathrm{a}}$ & $1.00 \pm 0.01^{\mathrm{a}}$ & $0.94 \pm 0.01^{\mathrm{a}}$ & $0.95 \pm 0.04^{a}$ & $0.95 \pm 0.11^{a}$ \\
\hline
\end{tabular}

\subsection{Swelling and WVP}

The water absorption capacity of the WPI film, expressed as the degree of swelling, increased modestly with OFA, but remarkably $(>2.3$-fold, $p<0.05$ ) by OTA (Table 2$)$. It appears that an equilibrium level was already reached with $2.5 \%$ phenolics, as no additional effect was produced at the higher concentration $(5.0 \%)$. The changes may be related to the microstructure of the film matrix, such as porosity, and the hydrophilicity of the protein material after crosslinking [34]. Although both of the oxidized phenols promoted protein crosslinking, this modification had no measurable effect on water vapor permeability (WVP), due to the hydrophilic nature of the WPI film, which is similar to the finding reported previously [35]. The arrangement of protein molecules, film microstructure, and plasticizers (e.g., glycerol) also affected the WVP. It is noteworthy that the comparison of phenol treatment effects in the present study was made under a specialized condition ( $50 \%$ $\mathrm{RH}$ at $23{ }^{\circ} \mathrm{C}$ and $12 \mathrm{~h}$ ). The values obtained may be subject to change under other $\mathrm{RH}$ conditions, since the water vapor transmission rate may be affected.

\subsection{Microstructure}

To explain the influence of OFA and OTA on the functional properties of WPI films, the interior and surface structures of the prepared films were examined by scanning electron microscopy (SEM) and atomic force microscopy (AFM), respectively. The cross-sectional SEM micrograph of the control WPI film was relatively orderly and uniform (Figure 2A); the OFA-treated WPI film appears to be more delicate, with continuous protein strands (Figure 2B), while the OTA treatment caused protrusions, ridges, and pores in the film (Figure 2C). These structural variations may reflect the crosslinking behavior of oxidized phenols, and explain the enhanced mechanical (TS, EBA, and Young's modulus) and water absorption properties (Table 2). The structure-functionality relationship of protein-based films has also been reported in other studies, for example, polysaccharide-included whey protein films [36].

Furthermore, the morphological images of the WPI films, acquired by AFM, exhibited considerable differences due to oxidized phenol treatments. Remarkably, the maximum height scale of the protein aggregates in the 2.5\% OTA-treated WPI film (Figure $2 \mathrm{C}^{\prime}$ ) increased from $5 \mathrm{~nm}$ (control film; Figure $\left.2 \mathrm{~A}^{\prime}\right)$ to $15 \mathrm{~nm}(p<0.05)$. Meanwhile, the aggregates became rougher and more protruding. Other researchers also found that the addition of oxidized sinapic acid resulted in more clustered areas compared to the pure WPI film [37]. On the other hand, for the WPI film treated with OFA (Figure 2B'), despite the slightly increased roughness, the maximum height of the aggregates remained at approximately $5 \mathrm{~nm}$. These morphological changes were due to the further aggregation of oxidized polyphenols in the film formation process, after the crosslinking of the WPI. The AFM results corroborated with SDS-PAGE, which showed markedly increased crosslinking of WPI in the presence of OTA and moderate crosslinking caused by OFA (Figure 1). 

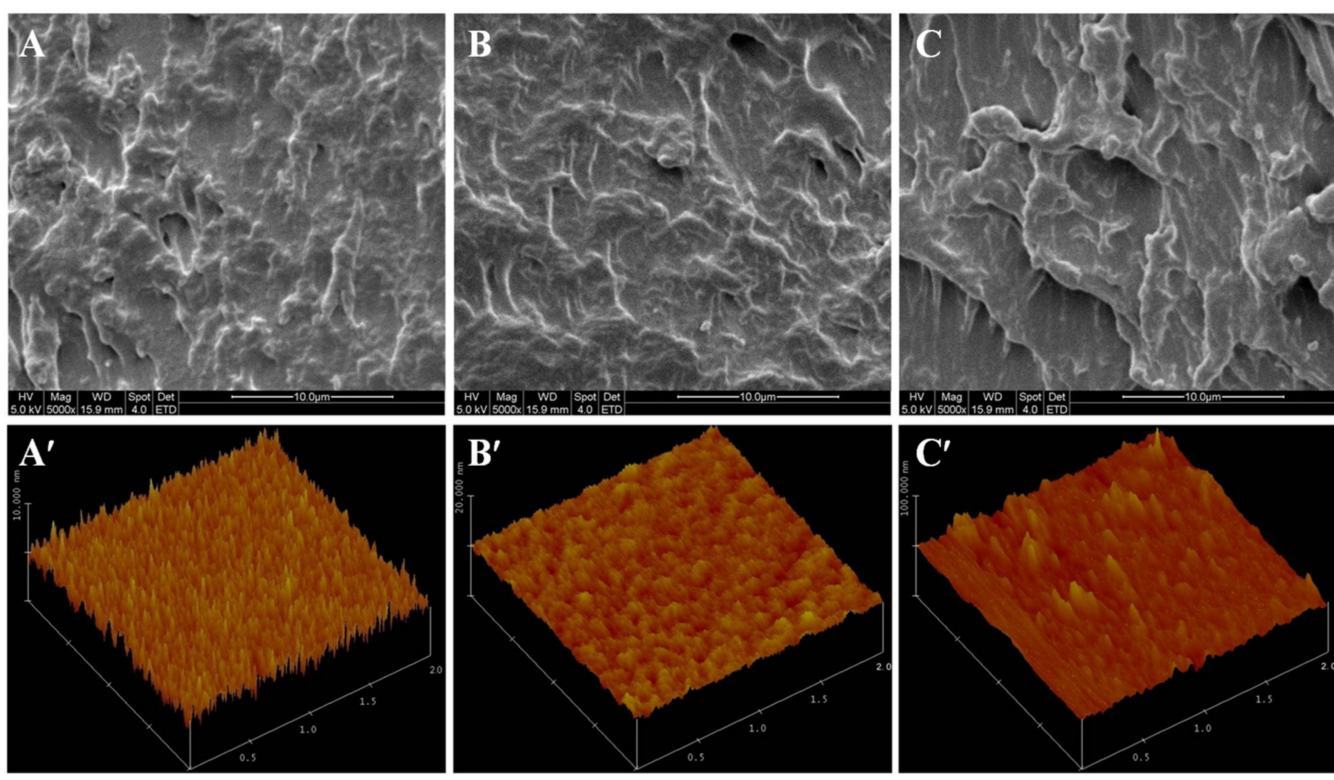

Figure 2. Cross-section SEM images (upper panel) and AFM surface images (lower panel) of control (A, $\left.\mathbf{A}^{\prime}\right), 2.5 \%$ oxidized ferulic (OFA; B, $\left.\mathbf{B}^{\prime}\right)$ and tannic (OTA; C, $\left.\mathbf{C}^{\prime}\right)$ acid-treated WPI films.

\subsection{Light Transmission and Transparency}

Apart from preventing gas exchange $\left(\mathrm{O}_{2}, \mathrm{CO}_{2}\right.$, water vapor, etc.), blocking the absorption of light is also an important property of edible films. As shown in Table 3, all of the WPI films resisted penetration by UV light (200 and $280 \mathrm{~nm})$. However, the OFA- and OTA-treated films had markedly reduced light transmission at 350 and $400 \mathrm{~nm}$, and the efficacy was phenolic dose-dependent, i.e., the higher the concentration oxidized phenols, the stronger the blocking effect. In the wavelength of 500-800 nm, the film formed with the crosslinking OTA still showed a respectable light-blocking effect, while the effect of OFA was poor. Film transparency decreased at any OTA concentration, while OFA had no effect. Due to the presence of oxidized polyphenols, the OTA-treated WPI film was darker than the OFA-treated film (brown). These films could be potentially used to package photosensitive foods, such as those rich in unsaturated fatty acids and susceptible to pigmentation, thus fulfilling the diversity requirements for food packaging materials [6].

Table 3. Light transmittance and transparency of oxidized ferulic (OFA) and tannic (OTA) acid-treated WPI films.

\begin{tabular}{|c|c|c|c|c|c|c|c|c|}
\hline \multirow{2}{*}{ Treatment } & \multicolumn{7}{|c|}{ Light Transmittance (\%) at Different Wavelengths (nm) } & \multirow{2}{*}{ Transparency } \\
\hline & 200 & 280 & 350 & 400 & 500 & 600 & 800 & \\
\hline $0 \%$ & 0 & 0 & $70.7 \pm 2.0^{\mathrm{a}}$ & $78.5 \pm 1.8^{\mathrm{a}}$ & $82.9 \pm 1.7^{\mathrm{a}}$ & $85.0 \pm 1.6^{\mathrm{a}}$ & $89.0 \pm 1.6^{\mathrm{a}}$ & $1.0 \pm 0.1^{\mathrm{c}}$ \\
\hline $2.5 \%$ OFA & 0 & 0 & $12.7 \pm 0.5^{b}$ & $67.1 \pm 3.7^{b}$ & $80.2 \pm 4.4^{\mathrm{a}}$ & $83.0 \pm 4.2^{\mathrm{a}}$ & $87.7 \pm 3.7^{\mathrm{a}}$ & $1.1 \pm 0.3^{c}$ \\
\hline $5.0 \%$ OFA & 0 & 0 & $0.4 \pm 0.3^{\mathrm{e}}$ & $44.9 \pm 5.1^{\mathrm{c}}$ & $80.5 \pm 0.4^{\mathrm{a}}$ & $84.1 \pm 0.5^{a}$ & $88.8 \pm 0.3^{a}$ & $1.1 \pm 0.0^{\mathrm{c}}$ \\
\hline $2.5 \%$ OTA & 0 & 0 & $8.9 \pm 0.9^{c}$ & $29.7 \pm 1.8^{\mathrm{d}}$ & $58.4 \pm 2.3^{b}$ & $69.2 \pm 2.6^{b}$ & $77.5 \pm 2.6^{b}$ & $2.7 \pm 0.3^{b}$ \\
\hline $5.0 \%$ OTA & 0 & 0 & $2.4 \pm 0.7^{\mathrm{d}}$ & $14.7 \pm 2.8^{\mathrm{e}}$ & $45.0 \pm 4.7^{c}$ & $59.3 \pm 4.9^{c}$ & $69.9 \pm 4.1^{c}$ & $4.5 \pm 0.7^{a}$ \\
\hline
\end{tabular}

${ }^{\mathrm{a}-\mathrm{c}}$ Means $\pm \mathrm{SD}(n=3)$ in the same column that do not share a common superscript differ significantly $(p<0.05)$.

\subsection{Thermal Properties}

The thermal melting profile of protein matrix films is an important property for industrial applications (e.g., as edible pouches for instant food and dry ingredients), where heat resistance and sealing strength must be considered [38]; the glass transition temperature of the protein material is one of the determinant factors [39]. Figure 3 displays the DSC melting profiles of the control and oxidized phenol-crosslinked WPI films that were subjected to heating from 25 to $260^{\circ} \mathrm{C}$. The thermal curves can be divided into two temperature zones according to rate of heat input. A small endotherm was recorded 
immediately above $150{ }^{\circ} \mathrm{C}$ (peak a), which can be attributed to the molecular transformation of weak interaction forces or low-order structures [40], including the melting of the partially crystalline/amorphous whey protein [41]. The peak was attenuated in OFAand OTA-crosslinked WPI films when compared with the control, suggesting a stronger water-binding capacity in the phenol-crosslinked films. A major endothermic transition occurred in the temperature region of $210-240{ }^{\circ} \mathrm{C}$ (peak b). The destruction of ordered molecular structures (e.g., hydrogen bonds) and the possible thermal decomposition of polypeptide chains, along with the volatilization of glycerol, may be responsible for this transition $[42,43]$. While the effect of OFA on this melting temperature was small $\left(2-5^{\circ} \mathrm{C}\right.$, Figure $3 \mathrm{~A})$, that of OTA was remarkable $\left(20-25{ }^{\circ} \mathrm{C}\right.$ increases, Figure $\left.3 \mathrm{~B}\right)$, in agreement with the stronger crosslinking effect of OTA, as shown previously (Figure 1 ), with a more rigid film matrix (Figure 2). With both OFA and OTA, the enthalpy of transition for peak two also decreased from $111 \mathrm{~J} / \mathrm{g}$ (control) to 86-108 J/g and 97-102 J/g, respectively, further suggesting a less ordered structure with the combined effect of the $\mathrm{C}-\mathrm{N}$ or $\mathrm{C}-\mathrm{S}$ covalent bonds in these phenol-crosslinked protein films. The temperature range of the thermal scan in the present study encompasses the temperatures applied to whey protein film sealing under an appropriate jaw pressure, e.g., 296 or $445 \mathrm{kPa}$ [41] and $293 \mathrm{kPa}$ [44]. It is not clear how the oxidized phenolic treatments would affect the sealability of WPI; this should be investigated in future research.
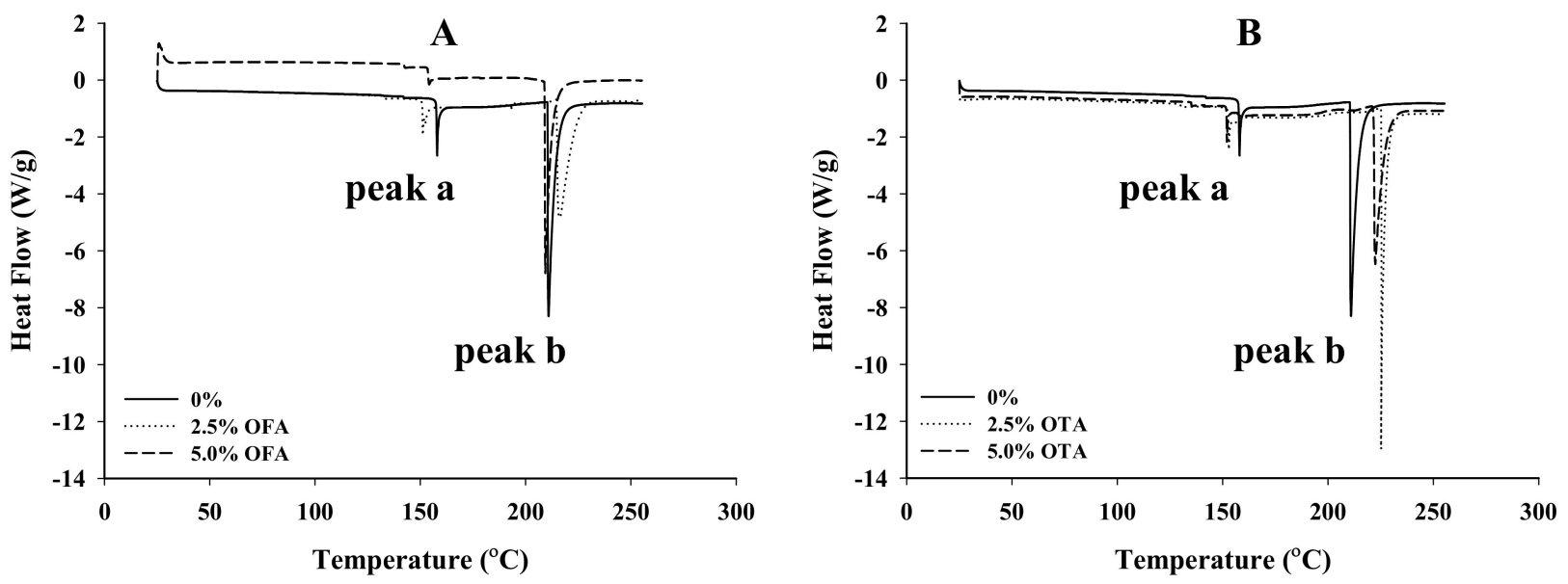

Figure 3. Differential scanning calorimetry thermograms of $2.5 \%$ and $5.0 \%$ oxidized ferulic (OFA; A) and tannic (OTA; B) acid-treated WPI films.

\subsection{Protein Leachability}

As an edible packaging material, protein-based films are digestible and hydratable in aqueous solutions. Unlike synthetic plastic polymer films, protein films are formed primarily through non-covalent interactions, although covalent bonds can be introduced through polyphenol crosslinking. The analysis of proteins that can readily leach into aqueous solutions can provide important guidance for practical applications [3,5]. As shown in Figure 4, the leaching rate of the control film at pH 3.0-7.0 was 13-21\%. The leaching rates of the films formed with $2.5 \%$ and $5 \%$ OFA-crosslinked WPI were similar to the control, over the same $\mathrm{pH}$ range. However, while showing no difference from the control and OFA-treated films at $\mathrm{pH}$ 3.0-5.0, the protein leachability of the OTA-crosslinked films more than doubled at $\mathrm{pH} 6.0$ and 7.0 when compared with other films. This high degree of protein leaching may be explained by the porosity of the OTA-crosslinked films (Figure 2). Due to the strong aggregation caused by OTA crosslinking, a heterogeneous structure, instead of an interactive, continuous, and well-connected WPI film matrix, would be conducive to protein leaching. The inter-polypeptide electrostatic repulsive forces at $\mathrm{pH} 6.0$ and 7.0 would facilitate protein release from the film matrix. 


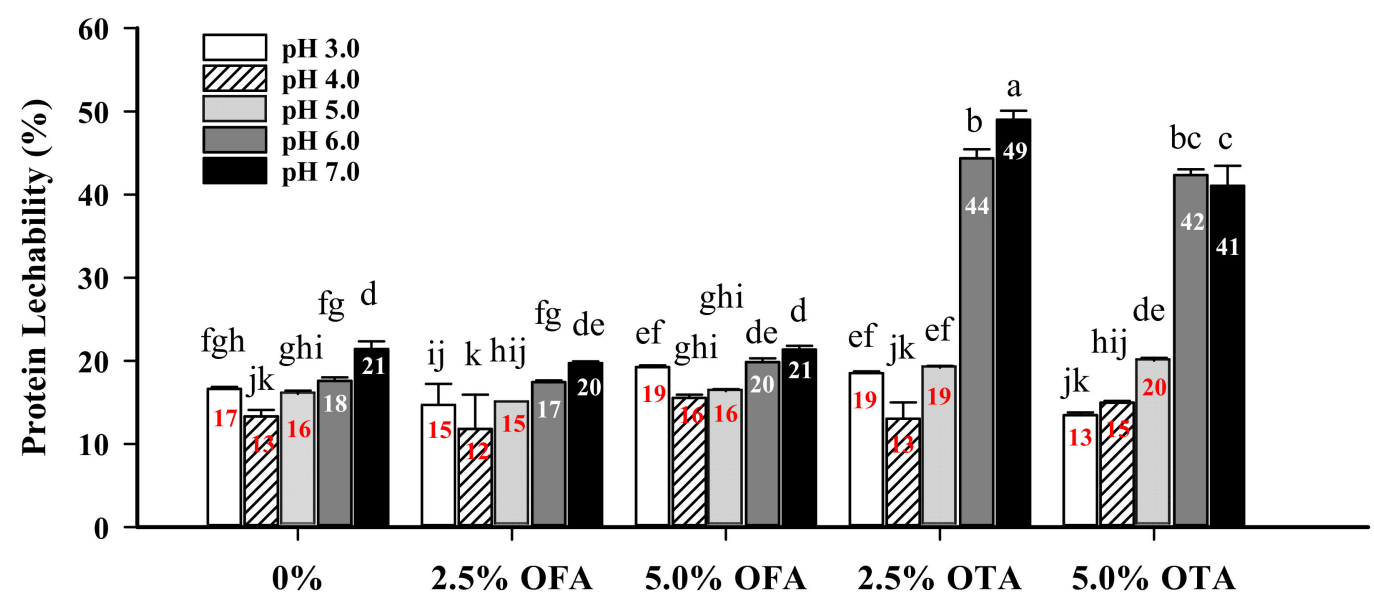

Figure 4. Protein leachability of $2.5 \%$ and $5.0 \%$ oxidized ferulic (OFA) and tannic (OTA) acid-treated WPI films at different $\mathrm{pH}$ levels. a-k: means without a common letter differ significantly $(p<0.05)$. Numbers inside the bars denote mean specific values of film protein leachability.

\subsection{Digestibility}

In vitro pepsin $\rightarrow$ pancreatin sequential digestion was carried out to monitor the digestion behavior of WPI films, and elucidate the oxidized phenol crosslinking effect. As summarized in Table 4, generally, the digestibility increased with time, reaching $85.6 \%$ for the control and $65.9-91.0 \%$ for the phenol-treated film samples. However, the effects of phenols were noticeably variable; they slightly suppressed the WPI digestion by pepsin, but promoted the digestion by pancreatin upon extended incubation (180-240 min), except for the 5\% OTA-treated film. The 5\% OFA- and OTA-treated films were generally more digestible than $2.5 \%$ by pancreatin. It has been reported that unmodified whey protein components were weakly susceptible to pepsin cleavage $[45,46]$. The decreased digestibility for most phenol-treated films was likely caused by the chemical bonds formed in the films (e.g., $\mathrm{C}-\mathrm{N}$ and $\mathrm{C}-\mathrm{S}$ ) that were unrecognizable by the enzyme. The slight temporary decline in the measured digestion rate, from 30 to $60 \mathrm{~min}$, of pepsin incubation may be the result of the hydrophobic aggregation of partially hydrolyzed/unfolded $\beta \mathrm{Lg}$, as such phenomena have been observed by a number of other researchers $[47,48]$.

Table 4. In vitro sequential digestion rate of oxidized ferulic (OFA) and tannic (OTA) acid-treated WPI films ${ }^{1}$.

\begin{tabular}{|c|c|c|c|c|c|c|c|c|}
\hline \multirow{3}{*}{ Digestion } & \multirow{3}{*}{ Treatment } & \multicolumn{7}{|c|}{ Hydrolysis Time (min) } \\
\hline & & \multicolumn{3}{|c|}{ Pepsin } & \multicolumn{4}{|c|}{ Pancreatin } \\
\hline & & $0^{2}$ & & 60 & 90 & 120 & 180 & 240 \\
\hline \multirow{2}{*}{$\begin{array}{l}4 \% \text { Pepsin }(1 \text { h } 37 \\
\left.\quad{ }^{\circ} \mathrm{C}, \mathrm{pH} 2.0\right)\end{array}$} & $0 \%$ & $\left(35.2^{a}\right)$ & $56.0 \pm 1.4^{\mathrm{a}}$ & $44.8 \pm 0.6^{\mathrm{a}, \mathrm{b}}$ & $56.0 \pm 6.2^{\mathrm{a}}$ & $72.7 \pm 3.7^{\mathrm{b}}$ & $70.0 \pm 2.6^{c}$ & $85.8 \pm 0.6^{b}$ \\
\hline & $2.5 \%$ OFA & $\left(32.3^{a, b}\right)$ & $47.1 \pm 0.3^{\mathrm{b}}$ & $44.0 \pm 0.3^{\mathrm{a}, \mathrm{b}}$ & $48.0 \pm 2.8^{b}$ & $62.2 \pm 0.9^{c}$ & $81.1 \pm 0.3^{b}$ & $91.0 \pm 4.6^{\mathrm{a}}$ \\
\hline$\downarrow$ & $5.0 \%$ OFA & $\left(29.0^{b}\right)$ & $44.1 \pm 0.3^{c}$ & $46.6 \pm 3.1^{\mathrm{a}}$ & $40.7 \pm 2.1^{c}$ & $57.9 \pm 0.7^{c, d}$ & $80.0 \pm 2.1^{b}$ & $82.4 \pm 2.8^{b}$ \\
\hline $4 \%$ Pancreatin $(4$ & $2.5 \%$ OTA & $\left(27.6^{\mathrm{b}}\right)$ & $49.3 \pm 1.4^{\mathrm{a}, \mathrm{b}}$ & $42.4 \pm 0.4^{b}$ & $54.7 \pm 1.9^{\mathrm{a}}$ & $77.2 \pm 2.2^{\mathrm{a}}$ & $89.0 \pm 2.2^{\mathrm{a}}$ & $89.1 \pm 0.4^{\mathrm{a}}$ \\
\hline $\left.\mathrm{h}, 37^{\circ} \mathrm{C}, \mathrm{pH} 7.5\right)$ & $5.0 \%$ OTA & $\left(28.5^{b}\right)$ & $40.7 \pm 0.4^{\mathrm{d}}$ & $28.4 \pm 0.4^{c}$ & $34.4 \pm 1.4^{\mathrm{d}}$ & $60.0 \pm 2.1^{c}$ & $62.1 \pm 2.8^{\mathrm{d}}$ & $65.9 \pm 0.4^{c}$ \\
\hline
\end{tabular}

${ }^{1}$ Digestion rate: \% of enzyme-released protein (into supernatant) over the total amount of unleached protein in the film. ${ }^{2}$ Time " 0 " values in parentheses denote unleached protein over total protein in the original film (\%), which were the base for digestion rate calculation.

a-d Means \pm SD $(n=3)$ in the same column that do not share a common superscript differ significantly $(p<0.05)$.

\section{Conclusions}

This study demonstrates that oxidized ferulic and tannic acids were able to improve the film-forming properties of WPI, through the oxidative modification of protein sidechain groups and the aggregation behavior. However, the performance of OFA and OTA differed. OFA increased the film pull strength (TS) and elasticity (Young's modulus), only at the higher treatment concentration $(5.0 \%)$, but improved the film extensibility (EAB) at both the $2.5 \%$ and $5.0 \%$ concentrations. In contrast, OTA greatly increased the pull 
strength and elasticity at both the $2.5 \%$ and $5.0 \%$ concentrations, but did not affect the film extensibility. The degree of oxidative changes in WPI, particularly covalent crosslinking, attributed to the changed film properties. The increased size of the protein aggregates and changed protein network structure accounted for, at least in part, the modified film properties. Such whey protein-based films were hydratable and remained largely digestible, despite the slight inhibition by OTA. These key findings strongly suggest the possibility to fabricate tunable and functionality-enhanced whey protein films. However, when aiming at the specific mechanical property(ies) that are desired to achieve, care must be taken to generate an appropriate level and type of protein oxidative modification with phenolic compounds. This would allow the balanced protein crosslinking in developing the target structural characteristics of the protein film. It is conceivable that equally or more functional oxidizable phenolic acids than OFA or OTA exist, and possibly also flavonoids, which, when oxidized, will promote protein film formation. Further research is warranted to evaluate the practical application of such biodegradable films for the packaging and preservation of dry or semi-dry food materials and products.

Author Contributions: Conceptualization, Y.L.X.; methodology, data curation, formal analysis, Y.W.; validation, Y.L.X. and Y.W.; writing-original draft preparation, Y.W.; writing—review and editing, Y.L.X. All authors have read and agreed to the published version of the manuscript.

Funding: The joint effort was supported by the USDA National Institute of Food and Agriculture of the USA (Hatch Project 1020736).

Institutional Review Board Statement: Not applicable.

Informed Consent Statement: Not applicable.

Data Availability Statement: The data presented in this study are as described in the individual figures and tables.

Acknowledgments: Author Wang wishes to acknowledge the opportunity to study and conduct the research at the University of Kentucky.

Conflicts of Interest: The authors declare no conflict of interest.

\section{References}

1. Nilsen-Nygaard, J.; Fernández, E.N.; Radusin, T.; Rotabakk, B.T.; Sarfraz, J.; Sharmin, N.; Sivertsvik, M.; Sone, I.; Pettersen, M.K. Current status of biobased and biodegradable food packaging materials: Impact on food quality and effect of innovative processing technologies. Compr. Rev. Food Sci. Food Saf. 2021, 20, 1333-1380. [CrossRef]

2. Ramos, Ó.L.; Fernandes, J.; da Silva, S.B.; Pintado, M.M.; Malcata, F. Edible Films and Coatings from Whey Proteins: A Review on Formulation, and on Mechanical and Bioactive Properties. Crit. Rev. Food Sci. Nutr. 2012, 52, 533-552. [CrossRef]

3. Wang, Y.; Xiong, Y.L.; Rentfrow, G.K.; Newman, M.C. Oxidation promotes cross-linking but impairs film-forming properties of whey proteins. J. Food Eng. 2013, 115, 11-19. [CrossRef]

4. Xu, Y.; Wang, Y.; Zhang, T.; Mu, G.; Jiang, S.; Zhu, X.; Tuo, Y.; Qian, F. Evaluation of the properties of whey protein films with modifications. J. Food Sci. 2021, 86, 923-931. [CrossRef] [PubMed]

5. Krochta, J.M. Edible protein films and coatings. In Food Proteins and Their Applications; Damodaran, S., Paraf, A., Eds.; Marcel Dekker Inc.: New York, NY, USA, 1997; pp. 529-549.

6. Mohamed, S.A.; El-Sakhawy, M.; El-Sakhawy, M.A.M. Polysaccharides, Protein and Lipid -Based Natural Edible Films in Food Packaging: A Review. Carbohydr. Polym. 2020, 238, 116178. [CrossRef]

7. Wihodo, M.; Moraru, C.I. Physical and chemical methods used to enhance the structure and mechanical properties of protein films: A review. J. Food Eng. 2013, 114, 292-302. [CrossRef]

8. Buchert, J.; Ercili-Cura, D.; Ma, H.; Gasparetti, C.; Monogioudi, E.; Faccio, G.; Mattinen, M.; Boer, H.; Partanen, R.; Selinheimo, E.; et al. Crosslinking Food Proteins for Improved Functionality. Annu. Rev. Food Sci. Technol. 2010, 1, 113-138. [CrossRef] [PubMed]

9. Rasouli, H.; Farzaei, M.H.; Khodarahmi, R. Polyphenols and their benefits: A review. Int. J. Food Prop. 2017, 20, 1700-1741. [CrossRef]

10. Ozdal, T.; Capanoglu, E.; Altay, F. A review on protein-phenolic interactions and associated changes. Food Res. Int. 2013, 51, 954-970. [CrossRef]

11. Akhtar, M.A.; Mariotti, C.E.; Conti, B.; Boccaccini, A.R. Electrophoretic deposition of ferulic acid loaded bioactive glass/chitosan as antibacterial and bioactive composite coatings. Surf. Coat. Technol. 2021, 405, 126657. [CrossRef] 
12. Hazer, B.; Ashby, R.D. Synthesis of a novel tannic acid-functionalized polypropylene as antioxidant active-packaging materials. Food Chem. 2021, 344, 128644. [CrossRef]

13. Cao, N.; Fu, Y.; He, J. Mechanical properties of gelatin films cross-linked, respectively, by ferulic acid and tannin acid. Food Hydrocoll. 2007, 21, 575-584. [CrossRef]

14. Kaczmarek, B.; Lewandowska, K.; Sionkowska, A. Modification of Collagen Properties with Ferulic Acid. Materials 2020, 13, 3419. [CrossRef]

15. Santos, T.; Filho, M.D.S.M.S.; Muniz, C.R.; Morais, J.P.S.; Kotzebue, L.R.V.; Pereira, A.L.S.; Mc Azeredo, H. Zein films with unoxidized or oxidized tannic acid. J. Sci. Food Agric. 2017, 97, 4580-4587. [CrossRef]

16. Picchio, M.L.; Linck, Y.G.; Monti, G.A.; Gugliotta, L.M.; Minari, R.J.; Igarzabal, C.I.A. Casein films crosslinked by tannic acid for food packaging applications. Food Hydrocoll. 2018, 84, 424-434. [CrossRef]

17. Xie, L.; Wehling, R.L.; Ciftci, O.; Zhang, Y. Formation of complexes between tannic acid with bovine serum albumin, egg ovalbumin and bovine beta-lactoglobulin. Food Res. Int. 2017, 102, 195-202. [CrossRef] [PubMed]

18. Balange, A.K.; Benjakul, S. Cross-linking activity of oxidised tannic acid towards mackerel muscle proteins as affected by protein types and setting temperatures. Food Chem. 2010, 120, 268-277. [CrossRef]

19. Liu, G.; Xiong, Y.; Butterfield, D. Chemical, Physical, and Gel-forming Properties of Oxidized Myofibrils and Whey- and Soy-protein Isolates. J. Food Sci. 2000, 65, 811-818. [CrossRef]

20. Lertittikul, W.; Benjakul, S.; Tanaka, M. Characteristics and antioxidative activity of Maillard reaction products from a porcine plasma protein-glucose model system as influenced by pH. Food Chem. 2007, 100, 669-677. [CrossRef]

21. Hayakawa, S.; Nakai, S. Relationships of hydrophobic and net change to the solubility of milk and soy proteins. J. Food Sci. 1985, 50, 486-491. [CrossRef]

22. Laemmli, U.K. Cleavage of structural proteins during the assembly of the head of bacteriophage T4. Nature 1970, 227, 680-685. [CrossRef] [PubMed]

23. ASTM. Standard test method for tensile properties of thin plastic sheeting. Standard designation D882-00. In Annual Book of ASTM Standards; ASTM: Philadelphia, PA, USA, 2000; pp. 160-168.

24. ASTM. Standard test methods for water vapor transmission of materials. Standard designation E96-E80. In Annual Book of ASTM Standards; ASTM: Philadelphia, PA, USA, 1989; pp. 730-739.

25. Ustunol, Z.; Mert, B. Water Solubility, Mechanical, Barrier, and Thermal Properties of Cross-linked Whey Protein Isolate-based Films. J. Food Sci. 2006, 69, FEP129-FEP133. [CrossRef]

26. Ma, Y.; Xiong, Y.L. Antioxidant and Bile Acid Binding Activity of Buckwheat Protein in Vitro Digests. J. Agric. Food Chem. 2009, 57, 4372-4380. [CrossRef]

27. Guo, A.; Xiong, Y.L. Myoprotein-phytophenol interaction: Implications for muscle food structure-forming properties. Compr. Rev. Food Sci. Food Saf. 2021, 20, 2801-2824. [CrossRef] [PubMed]

28. Stadtman, E.R. Protein oxidation and aging. Free. Radic. Res. 2006, 40, 1250-1258. [CrossRef] [PubMed]

29. Zhang, Q.; Cheng, Z.; Wang, Y.; Fu, L. Dietary protein-phenolic interactions: Characterization, biochemical-physiological consequences, and potential food applications. Crit. Rev. Food Sci. Nutr. 2020. [CrossRef] [PubMed]

30. Strauss, G.; Gibson, S.M. Plant phenolics as cross-linkers of gelatin gels and gelatin-based coacervates for use as food ingredients. Food Hydrocoll. 2004, 18, 81-89. [CrossRef]

31. Zhang, X.; Do, M.D.; Casey, P.; Sulistio, A.; Qiao, G.; Lundin, L.; Lillford, P.; Kosaraju, S. Chemical Modification of Gelatin by a Natural Phenolic Cross-linker, Tannic Acid. J. Agric. Food Chem. 2010, 58, 6809-6815. [CrossRef] [PubMed]

32. Stammers, M.; Niewczas, I.S.; Segonds-Pichon, A.; Clark, J. Mechanical stretching changes crosslinking and glycation levels in the collagen of mouse tail tendon. J. Biol. Chem. 2020, 295, 10572-10580. [CrossRef]

33. Keppler, J.K.; Schwarz, K.; van der Goot, A.J. Covalent modification of food proteins by plant-based ingredients (polyphenols and organosulphur compounds): A commonplace reaction with novel utilization potential. Trends Food Sci. Technol. 2020, 101, 38-49. [CrossRef]

34. Xue, F.; Zhao, M.; Liu, X.; Chu, R.; Qiao, Z.; Li, C.; Adhikari, B. Physicochemical properties of chitosan/zein/essential oil emulsion-based active films functionalized by polyphenols. Futur. Foods 2021, 3, 100033. [CrossRef]

35. Zhou, Y.; Zhu, X.; Zhang, C.; Chai, W.S.; Chew, K.W.; Du, A.; Show, P.L. Characterization of whey protein isolate and pectin composite film catalyzed by small laccase from Streptomyces coelicolor. Environ. Technol. Innov. 2020, 19, 100999. [CrossRef]

36. Tonyali, B.; Cikrikci, S.; Oztop, M.H. Physicochemical and microstructural characterization of gum tragacanth added whey protein based films. Food Res. Int. 2018, 105, 1-9. [CrossRef] [PubMed]

37. Yang, J.; Roozalipour, S.P.L.; Berton-Carabin, C.C.; Nikiforidis, C.V.; van der Linden, E.; Sagis, L.M. Air-water interfacial and foaming properties of whey protein sinapic acid mixtures. Food Hydrocoll. 2021, 112, 106467. [CrossRef]

38. Kokoszka, S.; Debeaufort, F.; Lenart, A.; Voilley, A. Water vapour permeability, thermal and wetting properties of whey protein isolate based edible films. Int. Dairy J. 2010, 20, 53-60. [CrossRef]

39. Yilmaz, K.; Turhan, S.; Saricaoglu, F.T.; Tural, S. Improvement of physicochemical, mechanical, thermal and surface properties of anchovy by-product protein films by addition of transglutaminase, and the correlation between secondary structure and mechanical properties. Food Packag. Shelf Life 2020, 24, 100483. [CrossRef]

40. Nuthong, P.; Benjakul, S.; Prodpran, T. Characterization of porcine plasma protein-based films as affected by pretreatment and cross-linking agents. Int. J. Biol. Macromol. 2009, 44, 143-148. [CrossRef] [PubMed] 
41. Kim, S.-J.; Ustunol, Z. Thermal Properties, Heat Sealability and Seal Attributes of Whey Protein Isolate/Lipid Emulsion Edible Films. J. Food Sci. 2001, 66, 985-990. [CrossRef]

42. Jafari, S.M.; Khanzadi, M.; Mirzaei, H.; Dehnad, D.; Chegini, F.K.; Maghsoudlou, Y. Hydrophobicity, thermal and micro-structural properties of whey protein concentrate-pullulan-beeswax films. Int. J. Biol. Macromol. 2015, 80, 506-511. [CrossRef]

43. Kadam, D.M.; Thunga, M.; Wang, S.; Kessler, M.; Grewell, D.; Lamsal, B.; Yu, C. Preparation and characterization of whey protein isolate films reinforced with porous silica coated titania nanoparticles. J. Food Eng. 2013, 117, 133-140. [CrossRef]

44. Janjarasskul, T.; Tananuwong, K.; Phupoksakul, T.; Thaiphanit, S. Fast dissolving, hermetically sealable, edible whey protein isolate-based films for instant food and/or dry ingredient pouches. LWT 2020, 134, 110102. [CrossRef]

45. Kananen, A.; Savolainen, J.; Mäkinen, J.; Perttilä, U.; Myllykoski, L.; Pihlanto-Leppälä, A. Influence of chemical modification of whey protein conformation on hydrolysis with pepsin and trypsin. Int. Dairy J. 2000, 10, 691-697. [CrossRef]

46. Peña-Ramos, E.; Xiong, Y. Antioxidative Activity of Whey Protein Hydrolysates in a Liposomal System. J. Dairy Sci. 2001, 84, 2577-2583. [CrossRef]

47. Ma, R.; Lin, Z.; Wu, Y.; Gao, Z.; Hu, B.; Xu, L.; Fang, Y.; Nishinari, K. Modulating the in vitro gastric digestion of heat-induced beta-lactoglobulin aggregates: Incorporation with polysaccharide. Food Chem. 2021, 354, 129506. [CrossRef]

48. Otte, J.; Lomholt, S.B.; Halkier, T.; Qvist, K.B. Identification of Peptides in Aggregates Formed during Hydrolysis of $\beta$ Lactoglobulin B with a Glu and Asp Specific Microbial Protease. J. Agric. Food Chem. 2000, 48, 2443-2447. [CrossRef] [PubMed] 